\title{
Autism Research in Iran: A Scientometric Study
}

\author{
Hadi Zarafshan, ${ }^{1,}{ }^{*}$ Mohammad Reza Mohammadi, ${ }^{1}$ Seyed Abbas Motevalian, ${ }^{2}$ Farid Abolhassani, ${ }^{3}$ Ali
}

Khaleghi, ${ }^{1}$ and Vandad Sharifi ${ }^{1}$

${ }^{1}$ Psychiatry \& Psychology Research Center, Tehran University of Medical Sciences, Tehran, Iran

${ }^{2}$ Iran University of Medical Sciences, Tehran, Iran

${ }^{3}$ Tehran University of Medical Sciences, Tehran, Iran

"Corresponding author: Hadi Zarafshan, Psychiatry \& Psychology Research Center, Tehran University of Medical Sciences, Tehran, Iran. Tel: +98-2155421959, E-mai: h-zarafshan@razi.tums.ac.ir

Received 2016 June 01; Revised 2016 August 14; Accepted 2016 October 02.

\begin{abstract}
Context: We aimed to conduct a scientometric study by investigating published papers of Iranian researchers on autistic disorders. Evidence Acquisition: We conducted a systematic review of the literature to retrieve all relevant studies on autism that are published by Iranian researchers. Seven databases were searched, of which three were local Iranian databases (Magiran, SID and Irandoc), and four were widely used English language databases (PubMed, Scopus, ProQuest and PsycInfo). Bibliometric information of all papers was extracted.

Results: Two hundred and six (95 Persian and 111 English) papers published between 1979 and 2015 were retrieved. Comparison between subject areas showed that non-pharmacological intervention and biological studies had the largest number with 64 and 61 papers, respectively. Among universities, Tehran University of Medical Sciences with 81 articles was most productive, and among the research centers, psychiatry and psychology research center (Tehran University of Medical Sciences) with 32 articles was the most productive research center.

Conclusions: The trends of research in the field of autism among Iranian researchers have the same patterns as the global trends. However, some important topics, such as prevalence, causes, services, and life span issues and the infrastructures have been studied less and should be considered in future studies. Moreover, it was revealed that we are faced with shortness of sources for research in this field, and the policy makers should consider this problem. We need to conduct researches that take into account our inner context, and the subject and quality of the research should be given more importance than the number.
\end{abstract}

Keywords: Autism, Iran, Scientometric Study

\section{Context}

Autistic disorders are neurodevelopmental conditions characterized by deficits in communication, stereotyped, and ritualistic behaviors and marked social skills deficiencies (1). We have witnessed the increasing prevalence of autistic disorders in the recent years. Some studies have reported that up to $1 \%$ of the population suffer from this illness (1-3). Despite being overlooked in the past, autistic disorders are now acknowledged as an incapacitating childhood disorder that has gained the attention of the public $(4,5)$.

This has led to expanding autism research in developed countries, with many governmental and private funding companies and institutions to allocate funds for autism research (6). In the United States, the Combating Autism Act authorized the expenditure of 950 million U.S. dollars for autism research over five years (7), and in the United Kingdom, nearly $£ 21$ million was devoted to autism research between 2007 and 2011 (8). However, most of these studies focused on areas such as biology of autism, risk factors and treatments, and other areas like life span issues and services have been less studied (9).

All of these endeavors (research and funding) should lead to changes in the life of people with autistic disorders and their families, and it can only be fulfilled when research efforts are directed towards most needed research areas with the potential of reduction of the burden of the illness (10).

The first step to achieve this goal was to determine the current status of autism research in every country that is well studied in other countries like USA and UK (10), but much less in developing countries like Iran. Iranian mental health research has been on the rise in the recent decades (11-13), but it is uncertain whether autism research keeps pace with other areas, and it is unclear which topics in autism research has attracted the attention of Iranian researchers. The available evidence shows that autism is almost prevalent in Iran as in many other countries (14, 15), but there is no study that show the current status of autism research in Iran. We aimed to conduct a scientometric study by investigating the published papers of Ira-

Copyright (c) 2016, Mazandaran University of Medical Sciences. This is an open-access article distributed under the terms of the Creative Commons 
nian researchers on autistic disorders. The findings of this study will show the present status and needs of research in the field of autism in Iran, and can improve health and research policy-making in Iran.

\section{Evidence Acquisition}

We conducted a systematic review to retrieve all autism related studies that have been published by Iranian researchers. Here, "Iranian researcher" is defined as the author of a research paper who is affiliated to a private or public center in Iran, whether academic, research or clinical. We searched seven databases, of which three were local Iranian databases (Magiran, SID and Irandoc), and four were widely used English databases (PubMed, Scopus, ProQuest and PsycInfo). Magiran and SID (Scientific information database) are databases that index almost all Persian scientific journals. Irandoc (Iranian research institute for information science and technology) is an institute affiliated to the ministry of science, research and technology of Iran, and has a comprehensive database that includes scientific papers, theses, and reports of scientific researches. All the searches were conducted through 16/03/2015. All original studies that were included in our study were published in a peer-reviewed journal in Persian or English in which one or more authors were affiliated to a center in Iran. Letters and editorials were excluded. We did not search and retrieve dissertations and the so called "gray literature"; however, we included conference papers if they were published in a scientific journal. The number of papers in each step is presented in Figure 1.

Bibliometric information of all papers, including name of the authors, number of the authors in each paper, affiliation of the first author, year of publication, number of publication per author, and funding sources were extracted. We also obtained additional information, including "international collaboration" (IC) of Iranian authors defined as studies in which there were one or more authors affiliated to centers outside Iran, and the "subject area" of the study that was categorized into seven areas adopted with minor adaptation from the criteria used in Pellicanom et al. (8) study. The categories were as follows: (1) biological studies that examined the biological and cognitive underpinnings of autism symptoms and disorders; (2) causes which included studies that aimed to identify genetic and environmental risk factors that may confer greater susceptibility to the development of autism; (3) family studies that evaluated the issues of caregiver stress and measures of quality of life for individuals with autism and their families, or assessed programs to help parents of children with autism to navigate the service system; (4) pharmacological intervention studies that

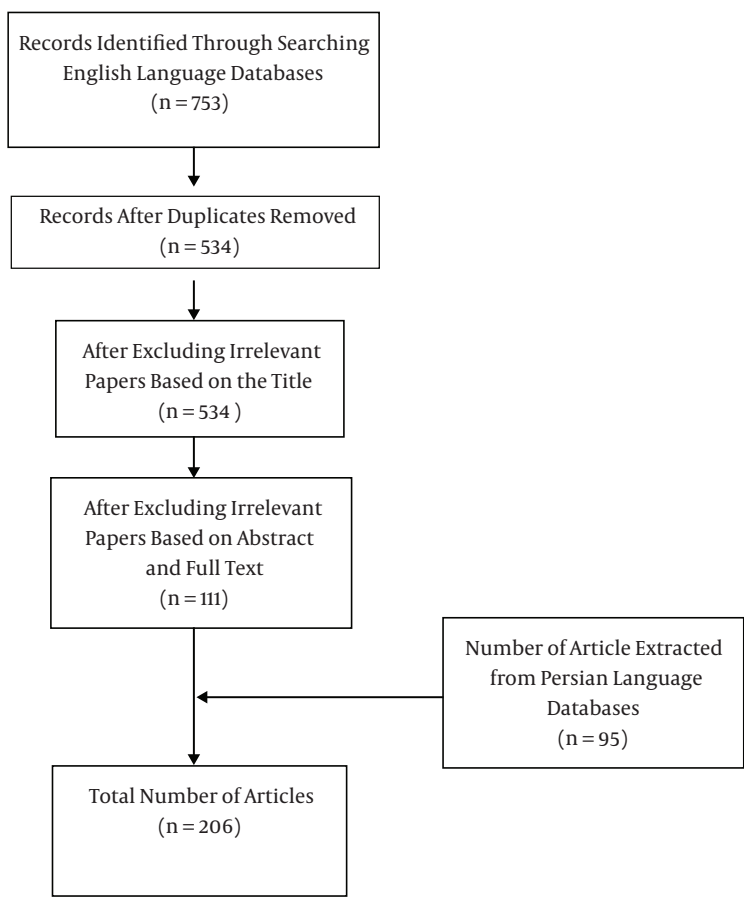

Figure 1. The Number of Papers in Each Step

evaluated pharmacological interventions for people with autistic disorders; (5) non-pharmacological intervention researches that evaluated any non-pharmacological interventions conducted on patients with autistic spectrum;(6) service researches that aimed to identify, develop and evaluate services and supports for people with autism and explored issues surrounding accessibility, cost- effectiveness and ease of transition between services; and 7) diagnostic and epidemiologic researches that aimed to recognize the symptoms and signs of autism, defined the typical characteristics and explored variation in the symptoms and severity associated with autism. We slightly changed the criteria used by Pellicano et al. because of the high number of family studies by Iranian researchers and differences between studies on pharmacological and non-pharmacological interventions between Persian and English language articles (see below). Each paper could be categorized into one subject area only.

Data extraction and categorization of the study subjects were conducted by two researchers independently, and they reached a consensus in case of any uncertainty about the appropriate subject area. 


\section{Results}

In Figure 2, we present the total number of articles (in both Persian and English). In sum, we retrieved 206 (95 Persian $l$ and 111 English) papers that were published by Iranian researchers between 1979 and 2015. Among English articles, 28 articles have been published in local English journals. As shown, the year 2013 was the most productive year for Iranian researchers in the field of autism. The first article in this field was published in 1979 by an Iranian researcher, Dr. Eshkevari (16), a psychiatrist who was affiliated to Tehran University of Medical Sciences. This paper was a case report about autism in monozygotic twins. Another case report was published by Dr. Eshkevari with the same subject in 1985 (17). After that, we were unable to find any publication on autism by Iranian researchers until 2000 (Figure 2).

The number of publications increased in the last two decades in terms of the total number and different subject areas (Figure 2). Comparison between subject areas showed that non-pharmacological intervention and biological studies had the largest number with 64 and 61 papers, respectively (Figure 3). We compared the total number of Persian and English articles in each subject area (Figure 4).

Most of the authors (320 authors) had only one published paper. As seen in Figure 5, most of the articles had 3 or 4 authors. Among all the published articles, only 23 articles had international collaborations. Iranian researchers collaborated with researchers from seven other countries, respectively, the USA in 11 articles (5.3\%), the UK in five articles (2.4\%), Australia in four articles (1.95\%), Canada, Sweden, Newzeland and Saudi Arabia each in one article (0.5\%) (Note: Iranian researchers collaborated with researchers from two countries in one article).

With regards to funding sources, only 42 articles, out of 206, mentioned that they had received financial support. Most of the papers were supported by TUMS (23 out of 42 , and other centers supported 1 - 4 papers.

In Table 1, we present five most productive universities and research centers according to the affiliation of the authors. Among universities, Tehran University of Medical Sciences with 81 articles was the most productive university, followed by Islamic Azad University with 32 articles. Among research centers, psychiatry and psychology research center (Tehran University of Medical Sciences), and research center for psychiatry and behavioral sciences (Shiraz University of Medical Science) were the most productive research centers with 32 and 19 articles, respectively.

\section{Conclusions}

The aim of this study was to examine the present status of research in the field of autism among Iranian researchers. Iranian researchers have published their works in both Persian and English journals. The total number of publications in the field of autism was 206, of which $46 \%$ $(n=95)$ were published in Persian journals and 54\% $(n=111)$ in English journals. Iranian researchers had more publications in English journals than in Persian journals, and this is in contrast with other areas of mental health research where most papers have been published in Persian journals $(12,13)$.

To keep up with the trend of global research in the field of autism, autism research in Iran has increased in recent years (Figure 2). Office of autism research coordination (OARC) has published an analysis of global autism publications (9). Based on this report, the number of global publications in the field of autism has increased rapidly after the year 2000. A sharp increase in this trend is seen in 2005 to 2007 period. Based on our findings, the number of publications of Iranian researchers has been steadily increasing since 2006 and peaked in 2013 with 57 publications. A new study has investigated the performance of Iranian psychology and psychiatry researchers that were published in Thomson Reuter's indexed journals (11). Based on this study, the number of publications by Iranian researchers has dramatically increased over the examined period (1967 and 2010) (11).

By reviewing the literature on autism researches across the globe, we can see a tendency toward areas like biology, risk factors and treatments $(6,8,9)$. Almost the same pattern can be seen in Iran, except risk factors that have not been well studied by Iranian researchers. It has been shown that the subject of research may be influenced by the global and, especially, American or European researchers. Among publications of Iranian researchers, biology and treatments (pharmacological and non-pharmacological) of autism have been studied more than other areas (Figure 3). With regards to publications in the treatment area, there is a huge difference between the Persian and English publications (Figure 4). Almost all the Persian publications (except one) focused on nonpharmacological treatments, while the subject of most English publications was pharmacological treatments (28 of all 46 publications). This is perhaps due to their higher chance of publication in English journals, or specific interests of the few prolific Iranian researchers.

Considering the increasing number of people with autism and bearing in mind their life-long needs, although biology has the largest proportion of publications, those conducted in the areas like services, life span issues and 
Figure 2. The Number of Articles That Are Published in English and Persian languages Compared to the Total Number of Publications

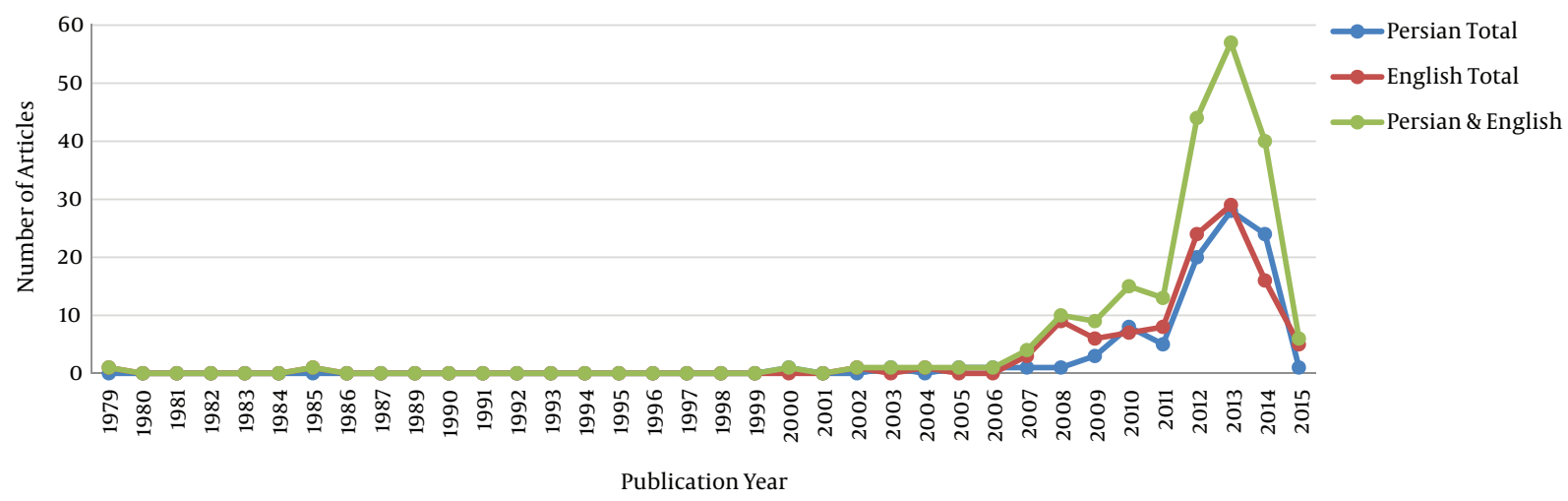

Persian \& English: the total number of articles published in both languages; total English articles: the total number of articles published in English; total Persian Articles: the total number of articles published in Persian.

Figure 3. Number of Articles in Each Subject Area

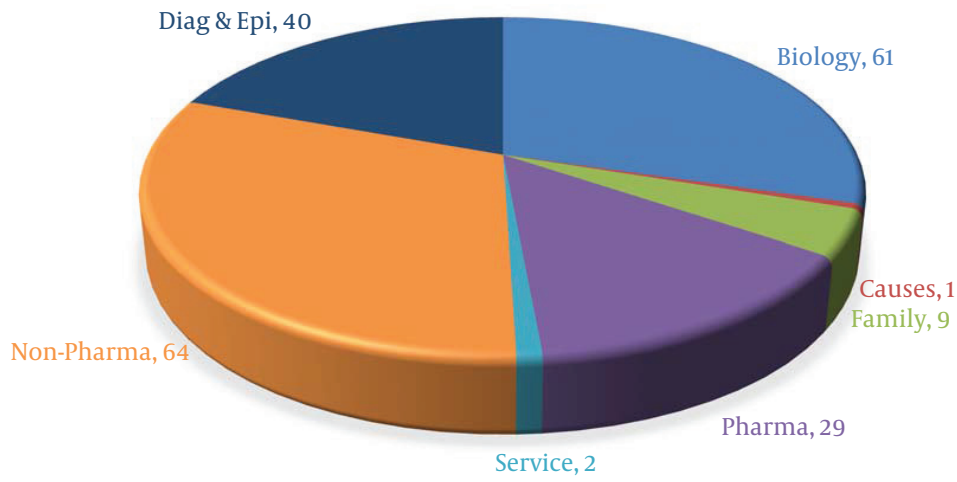

${ }^{*}$ In sum, 206 articles were published by Iranian researchers.

Figure 4. Comparison of the Total Number of Persian and English Articles in Each Subject Area

Persian Language Articles

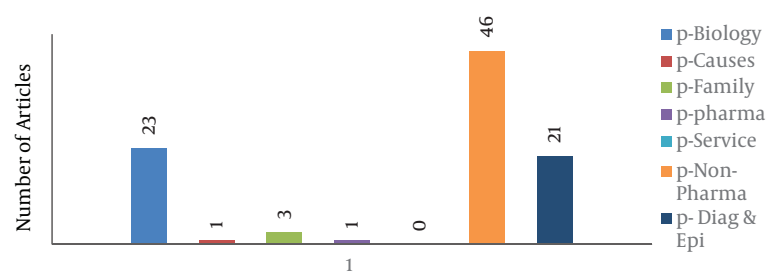

Subject Areas
Persian Language Articles

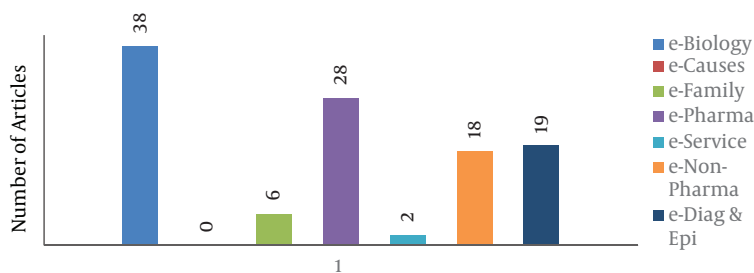

Subject Areas

p: Persian language; e: English language.

infrastructures had the highest fold growth among global publications $(8,9)$. Our findings revealed that these important research areas are almost completely neglected by Ira- nian researchers. Service research is similarly neglected in other mental health research (13). The only area that has been studied to some extent is familial issues. It may be 


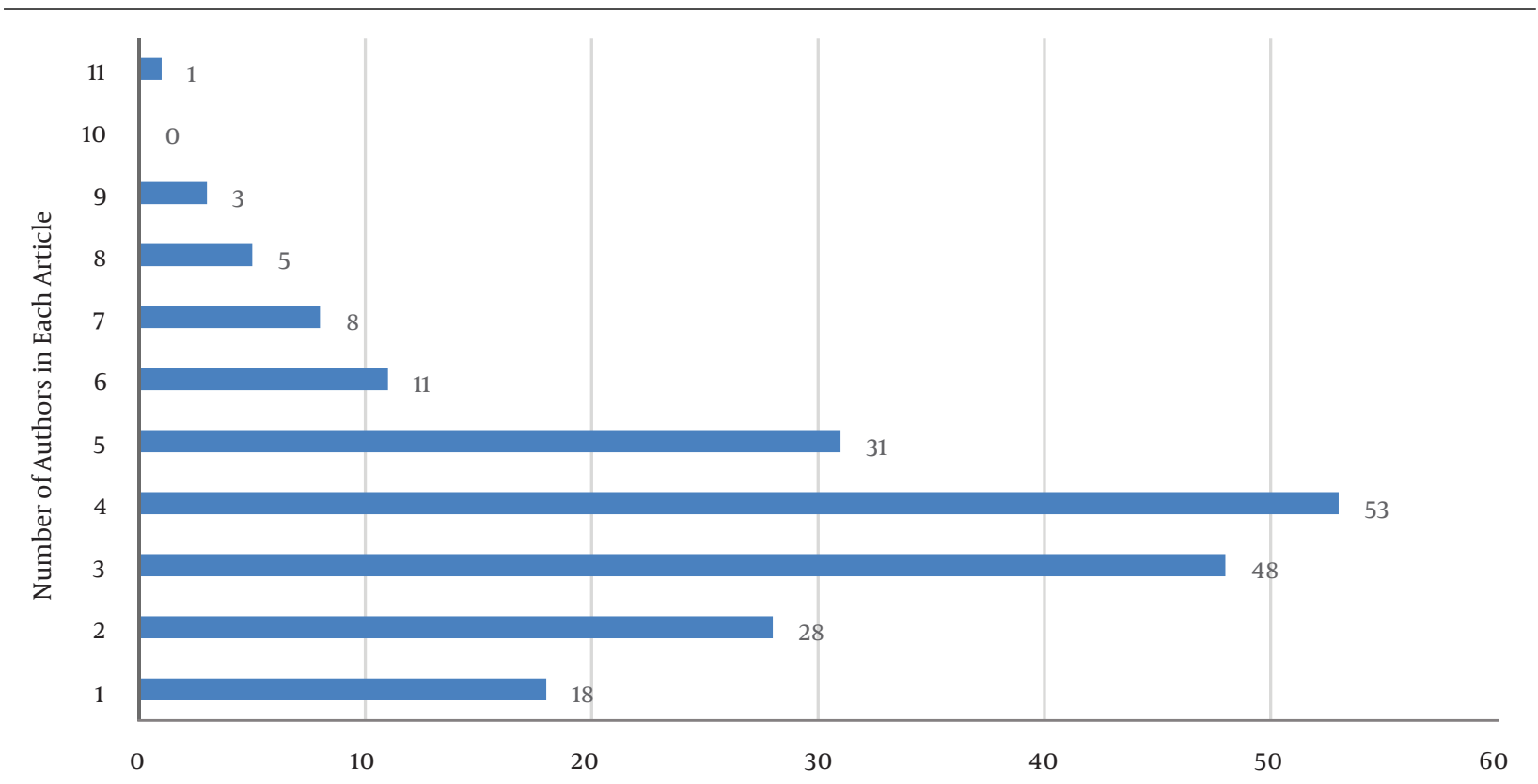

Number of Articles

Figure 5. The Number of Articles According to the Number of Authors in Each Paper

Table 1. Five Most Productive Universities and Research Centers

\begin{tabular}{|c|c|c|c|c|c|}
\hline \multirow[t]{2}{*}{ Rank } & \multicolumn{2}{|c|}{ Five Most Productive Universities } & \multirow[t]{2}{*}{ Rank } & \multicolumn{2}{|c|}{ Five Most Productive Research Centers } \\
\hline & University & Number of Publications & & Research Center & Number of Publications \\
\hline $\mathbf{1}$ & Tehran University of Medical Sciences & 81 & 1 & $\begin{array}{c}\text { Psychiatry and Psychology Research } \\
\text { Center, Tehran University of Medical } \\
\text { Sciences }\end{array}$ & 32 \\
\hline 2 & Islamic Azad University (all branches) & 32 & 2 & $\begin{array}{l}\text { Research Center for Psychiatry and } \\
\text { Behavioral Sciences, Shiraz University of } \\
\text { medical science }\end{array}$ & 19 \\
\hline 3 & $\begin{array}{c}\text { Shahid Beheshti University of Medical } \\
\text { Sciences }\end{array}$ & 31 & 3 & $\begin{array}{l}\text { Sports Medicine Research Center, Tehran } \\
\text { University of Medical Sciences }\end{array}$ & 8 \\
\hline 4 & University of Social Welfare & 30 & 4 & Institute for Cognitive Science Studies & 5 \\
\hline \multirow[t]{3}{*}{5} & Shiraz University of Medical Sciences & 29 & 4 & Institute of Medicinal Plants(ACECR) & 5 \\
\hline & & & 5 & $\begin{array}{c}\text { Pediatric Neurorehabilitation Research } \\
\text { Center, Tehran University of Social } \\
\text { Welfare and Rehabilitation Sciences }\end{array}$ & 4 \\
\hline & & & 5 & $\begin{array}{c}\text { Research Center for Behavioral Disorders } \\
\text { and Substance Abuse, Hamadan } \\
\text { University of Medical Sciences }\end{array}$ & 4 \\
\hline
\end{tabular}

partly due to its deep root and importance in Iranian culture where family is usually considered as the main source of care and support for children.

Most Iranian researchers had only one publication in the field of autism. Two researchers had 26 and 24 publications: One was a professor of child and adolescent psychiatry at Tehran University of Medical sciences, and the sec- ond a professor of child and adolescent psychiatry at Shiraz University of Medical sciences. It should be emphasized that only a few researchers have published most of the articles on autism and their interests may have influenced all the results.

Number of authors in each article and number of articles with international collaborations are considered as 
indicators of collaboration in scientometric studies (18). Based on our study, most articles had 3 or 4 authors (Figure 5). Only 21 articles were conducted by international collaboration (11.2\% of articles; note that if we consider only English articles, this percent is equal to $20.7 \%$ ). Analysis of international autism publications has shown that this rate was 20\% for all countries in 2010 (9). The percentage of Iranian publications with international collaboration is higher in other fields like psychology and psychiatry (11).

Only 42 articles mentioned that they had secured funds. Given that some articles did not refer to their sources of sponsorship, it is still very low compared to what happens in other countries. In countries like the U.S. and the U.K., large amount of resources were devoted to autism research by public and private organizations $(7,8)$. In Iran, Tehran University of Medical Sciences is acknowledged more than other centers as a source of sponsorship. It is also revealed that Iranian researchers are not that successful in obtaining international resources, as there were only three international organizations and each only sponsored one project.

Our study revealed that among universities and research centers that published articles in the field of autism, Tehran University of Medical Sciences and psychiatry and psychology research center (associated with Tehran University of Medical Sciences) were the most productive university and research center. This is in line with pervious scientometric studies. A study conducted by Yadollahi et al. (19) found that Tehran University of Medical Sciences is the most productive university among Iranian medical universities. Moreover, another study revealed that Tehran University of Medical Sciences is the most productive university in the field of psychology and psychiatry (11). This may be due to the fact that Tehran University of Medical Sciences is the biggest medical university in Iran and has a considerable number of faculty members that give rise to more scientific publications.

The trends of research in the field of autism among Iranian researchers almost keeps pace with global trends, but some important topics such as prevalence, causes, services, life span issues and infrastructures are less studied and should be taken into account in future researches. Based on our findings, inadequate funding can be assumed to be allocated to research in the field of autism. We need to conduct more on research in this field through main funding bodies in Iran, such as the national institute for medical research development (NIMAD), particularly on the subject areas that are much needed but less studied. Although there are more than 500 research centers in the ministry of health and medical education in Iran, no specific research centers are devoted to autism research. Another important issue is that international collaboration is poor among Iranian researchers in the field of autism that could be partly due to economic sanctions imposed on Iran in the past decades. Therefore, we should expand our relationship with research centers and universities that are active in the field of autism in other countries to increase the quality of researches and resources that are needed.

\section{Acknowledgments}

This study was a part of doctoral thesis of Hadi Zarafshan under the supervision of Dr. Vandad Sharifi and was supported by Tehran University of Medical Sciences.

\section{Footnotes}

Authors' Contribution: Hadi Zarafshan and Vandad Sharifi conceived and designed the evaluation. Hadi Zarafshan, Vandad Sharifi and Ali Khaleghi collected the clinical data. Hadi Zarafshan, Vandad Sharifi, Mohammad Reza Mohammadi, Seyed Abbas Motevalian and Farid Abolhassani interpreted the clinical data. Hadi Zarafshan and Vandad Sharifi performed the statistical analysis. Hadi Zarafshan drafted the manuscript. Hadi Zarafshan, Vandad Sharifi, Mohammad Reza Mohammadi, Seyed Abbas Motevalian and Farid Abolhassani revised it critically for important intellectual content. All authors read and approved the final manuscript.

Declaration of Interest: None declared.

Funding/Support: This study was a part of doctoral thesis of Hadi Zarafshan under the supervision of Dr. Vandad Sharifi and was supported by Tehran University of Medical Sciences.

\section{References}

1. American Psychiatric Association . DSM-5 Task Force. Diagnostic and statistical manual of mental disorders. 5 ed. Washington, D.C: American Psychiatric Association; 2013. p. 947.

2. Williams JG, Higgins JP, Brayne CE. Systematic review of prevalence studies of autism spectrum disorders. Arch Dis Child. 2006;91(1):8-15 doi: 10.1136/adc.2004.062083. [PubMed: 15863467].

3. Matson JL, Kozlowski AM. The increasing prevalence of autism spectrum disorders. Research in Autism Spectrum Disorders. 2011;5(1):418-25. doi: 10.1016/j.rasd.2010.06.004.

4. Singh J, Illes J, Lazzeroni L, Hallmayer J. Trends in US autism research funding. J Autism Dev Disord. 2009;39(5):788-95. doi: 10.1007/s10803 008-0685-0. [PubMed: 19148735].

5. Matson JL. Current status of differential diagnosis for children with autism spectrum disorders. Res Dev Disabil. 2007;28(2):109-18. doi: 10.1016/j.ridd.2005.07.005. [PubMed: 16516441].

6. Matson JL, LoVullo SV.Trends and topics in autism spectrum disorders research. Research in Autism Spectrum Disorders. 2009;3(1):252-7. doi: 10.1016/j.rasd.2008.06.005.

7. Insel T. Future directions: setting priorities to guide the federal research effort. Autism Spectrum Disorders. 2011:1361-8. 
8. Pellicanom L, Dinsmore A, Charman T. A Future Made Together: Shaping autism research in the UK. 2013.

9. Office of Autism Research Coordination (OARC) . NIoMHaTR, Inc. on behalf of the Interagency Autism Coordinating Committee (IACC). IACC/OARC Autism Spectrum Disorder Research Publications Analysis Report: The Global Landscape of Autism Research Department of Health and Human Services Interagency Autism Coordinating Committee website; 2012. Available from: http://iacc.hhs.gov/ publications-analysis/july2012/index.shtml.

10. Pellicano E, Dinsmore A, Charman T. What should autism research focus upon? Community views and priorities from the United Kingdom. Autism. 2014;18(7):756-70. doi: 10.1177/1362361314529627. [PubMed: 24789871].

11. Erfanmanesh M, Gholamhosseinzadeh Z, Jahromi RB. The Performance of Iranian Psychology and Psychiatry Researchers: A Scientometric Study. Collnet J Scientometrics Info Manag. 2013;7(2):161-72. doi: 10.1080/09737766.2013.832898.

12. Nejatisafa AA, Mohammadi MR, Sharifi V, Goodarzi RR, Izadian ES, Farhoudian A. Iran's Contribution to Child and Adolescent Mental HealthResearch (1973-2002): A Scientometric Analysis. Iran J Psychiatr. 2006;1(3):93-7.

13. Sharifi V, Rahimi Movaghar A, Mohammadi M, Goodarzi R, Izadian E,
Farhoudian A. Analysis of mental health research in the Islamic Republic of Iran over 3 decades: a scientometric study. East-MediterrHealth J. 2008 Sep-Oct;14(5):1060-9. [PubMed: 19161078].

14. Ghanizadeh A. A preliminary study on screening prevalence of pervasive developmental disorder in schoolchildren in Iran.J Autism Dev Disord. 2008;38(4):759-63. doi: 10.1007/s10803-007-0445-6. [PubMed: 17879153].

15. Samadi SA, Mahmoodizadeh A, McConkey R. A national study of the prevalence of autism among five-year-old children in Iran. Autism. 2012;16(1):5-14. doi: 10.1177/1362361311407091. [PubMed: 21610190].

16. Eshkevari HS. Early infantile autism in monozygotic twins. J Autism Dev Disord. 1979;9(1):105-9. [PubMed: 438110].

17. Salimi-Eshkevari H. Infantile autism in monozygotic twins. J Am Acad Child Psychiatry. 1985;24(5):643-6. [PubMed: 4045065].

18. Thonon F, Boulkedid R, Delory T, Rousseau S, Saghatchian M, van Harten W. Measuring the Outcome of Biomedical Research: A Systematic Literature Review. PLoS One. 2015;10(4):e122239. doi: 10.1371/journal.pone.0122239.

19. Yadollahi M, Haseli N, Shamsedini N, Yousefi S, Poostforoushfard A, Dehbozorgian F. Investigation of science production in Iran's type I universities of medical sciences, a 6-year assessment. J Health Manag Info. 2014;1(3):71-7. 